\title{
Consumo de matéria seca e desempenho de novilhas Nelore alimentadas com dietas contendo cana-de-açúcar hidrolisada
}

\author{
Dry matter intake and performance of Nellore heifers fed with hydrolyzed sugarcane
}

\author{
Regis Luis Missio ${ }^{I}$ Mauro Dal Secco de Oliveira ${ }^{I I}$ Mariana Paula Rossi Sforcini ${ }^{I}$ João Restle ${ }^{\text {III }}$

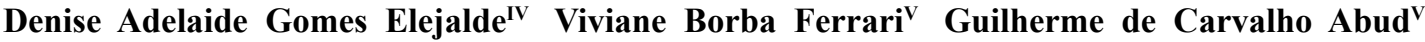

RESUMO

Objetivou-se avaliar o consumo de nutrientes e o desempenho de novilhas Nelore alimentadas com dietas contendo cana-de-açúcar in natura (CN) ou hidrolisada (CH) com $0,5 \%$ de $\mathrm{Ca}(\mathrm{OH})_{2}$ armazenada por 24, 48 e 72 horas. Foram utilizadas 24 novilhas com nove meses de idade e $119,6 \pm 8,1 \mathrm{~kg}$ de peso corporal inicial. $O$ delineamento experimental utilizado foi o inteiramente casualisado com quatro tratamentos e seis repetições. O consumo de matéria seca foi reduzido em $29 \%$ pela adição de $\mathrm{Ca}(\mathrm{OH})$, não sendo alterado pelo periodo de armazenamento da $\mathrm{CH}$. $\mathrm{O}$ consumo de cálcio foi incrementado $(P<0,05)$ pela utilização de $\mathrm{CH}$ nas dietas, mantendo níveis de ingestão aceitáveis. Novilhas alimentadas com CH armazenada por 24, 48 e 72 horas apresentaram, respectivamente, ganhos de peso 41,30 e $35 \%$ inferior $(P<0,05)$ àquelas alimentadas com $C N$. $O$ tratamento da cana-de-açúcar com $\mathrm{Ca}(\mathrm{OH})_{2}$ não é recomendado para alimentação de novilhas Nelore, em virtude de limitar a ingestão e reduzir o ganho de peso.

Palavras-chave: $\mathrm{Ca}(\mathrm{OH})_{2}$, consumo de cálcio, ganho de peso, valor nutritivo.

\section{ABSTRACT}

The study aimed to evaluate the nutrients intake and performance of Nellore heifers fed with chopped sugarcane, fresh (FS) or treated (HS) with $0.5 \%$ of $\mathrm{Ca}(\mathrm{OH})$, and stored during 24 , 48 or 72 hours. It was used twenty-four heifers with nine months age and $119.6 \pm 8.1 \mathrm{~kg}$ of initial body weight. The experimental design was completely randomized with four treatments and six replications. The dry matter intake showed an average reduction of $29 \%$ by adding $\mathrm{Ca}(\mathrm{OH})_{2}$, and didn't change with the storage period. Calcium intake was increased by the use of HS in the diet, while maintaining acceptable levels of intake. Heifers fed with HS stored during 24, 48 and 72 hours had, respectively, average daily weight gain of 41, 30 and 35\% lower than those fed with FS. The treatment of sugarcane with $\mathrm{Ca}(\mathrm{OH})_{2}$ is not recommended for feeding Nellore heifers, due to limited intake and lower weight gain.

Key words: $\mathrm{Ca}(\mathrm{OH})_{2}$, calcium intake, nutritional value, weight gain.

\section{INTRODUÇÃO}

A alimentação de bovinos no período de baixa disponibilidade das forragens tropicais preocupa não somente pelo aspecto nutricional, mas também pelo custo do volumoso que substitui o pasto na dieta. Para tanto, quando considerada a composição do custo com alimentação, os volumosos assumem participação importante, pois podem representar a maior parte da matéria seca da dieta. Nesse sentido, a utilização da cana-de-açúcar como volumoso para alimentação de ruminantes destaca-se pelo baixo custo da tonelada produzida, assim como pela elevada produção de matéria seca e energia na forma de carboidratos solúveis (principalmente sacarose), o que coincide com o período de escassez de forragem.

A utilização da cana-de-açúcar na alimentação de bovinos baseia-se no corte diário e fornecimento da forragem fresca aos animais. Todavia, esse procedimento tem dificultado a logística das propriedades, notadamente em confinamentos comerciais e propriedades leiteiras,

\footnotetext{
'Programa de Pós-graduação em Zootecnia, Universidade Estadual Paulista “Júlio de Mesquita Filho” (Unesp), Jaboticabal, SP, Brasil.

IIUnesp, Jaboticabal, SP, Brasil. E-mail: regisluismissio@gmail.com. Autor para correspondência.

"Universidade Federal do Tocantins (UFT), Araguaína, TO, Brasil.

IV Programa de Pós-graduação em Zootecnia, Universidade Federal do Rio Grande do Sul (UFRGS), Rio Grande do Sul, Brasil.

${ }^{\vee}$ Graduação em Zootecnia, Unesp, Jaboticabal, SP, Brasil.
} 
devido à quantidade de mão-de-obra e equipamentos necessários, bem como pelos custos envolvidos. Além disso, a cana-de-açúcar apresenta baixos teores de proteína bruta e minerais, fato que pode ser contornado pela utilização de ureia e mistura mineral. A cana-de-açúcar ainda apresenta baixa ingestão por ruminantes, fato associado à reduzida digestibilidade da fibra (MAGALHÃES et al., 2004). Em função disso, pesquisas têm sido desenvolvidas com intuito de melhorar as características nutritivas e diminuir a frequência de corte pelo armazenamento da cana-deaçúcar a partir de seu tratamento com óxido $(\mathrm{CaO})$ ou hidróxido de cálcio $\left(\mathrm{Ca}(\mathrm{OH})_{2}\right)$ (PINA et al., 2011; PANCOTI et al., 2011).

Apesar do número de estudos com canade-açúcar tratada com cales ter aumentado nos últimos anos, o número de informações a respeito dos efeitos da adição desses agentes hidrolizantes, bem como do armazenamento da cana hidrolisada sobre o consumo de alimento e desempenho de bovinos são incipientes, sendo os resultados reportados pela literatura contraditórios (MORAES et al., 2008; FREITAS et al., 2011; MISSIO et al., 2012a). Dessa forma, objetivou-se com esta pesquisa avaliar o consumo de nutrientes e o desempenho de novilhas Nelore alimentadas com dietas contendo cana-deaçúcar in natura ou tratada com hidróxido de cálcio e armazenada por diferentes períodos.

\section{MATERIAL E MÉTODOS}

Foram utilizadas 24 novilhas da raça Nelore com nove meses de idade e $119,6 \pm 8,1 \mathrm{~kg}$ de peso corporal inicial. Elas foram distribuídas ao acaso em quatro tratamentos constituídos pelas dietas experimentais (Tabela 1) com seis repetições, sendo o período experimental de 84 dias. As novilhas foram confinadas em baias individuais $\left(14 \mathrm{~m}^{2}\right)$ parcialmente cobertas, equipadas com bebedouros e comedouros e, adaptadas por 17 dias às dietas e instalações. No início do experimento e a cada 28 dias, os animais foram pesados individualmente após jejum de sólidos e líquidos por 14-16 horas e avaliados quanto ao escore corporal, considerando escala entre um (muito magro) e cinco (muito gordo).

O volumoso utilizado foi a cana-deaçúcar cv. IAC 86-2480 (ciclo precoce), com idade entre 10-12 meses, triturada em máquina forrageira

Tabela 1 - Composição química e percentual das dietas experimentais e volumosos.

\begin{tabular}{|c|c|c|c|c|c|c|c|c|}
\hline \multirow{2}{*}{ Nutrientes - Ingredientes } & \multicolumn{8}{|c|}{ - } \\
\hline & $\mathrm{CN}$ & $\mathrm{CH} 24$ & $\mathrm{CH} 48$ & $\mathrm{CH} 72$ & Cana & $\mathrm{C} 24$ & $\mathrm{C} 48$ & $\mathrm{C} 72$ \\
\hline Matéria seca (MS), \% MN & 51,50 & 51,32 & 51,71 & 25,97 & 25,67 & 27,38 & 28,33 & 25,97 \\
\hline Matéria mineral & 5,86 & 7,15 & 7,14 & 3,73 & 5,84 & 5,88 & 5,94 & 3,73 \\
\hline Extrato etéreo & 1,91 & 1,94 & 1,94 & 1,22 & 1,27 & 1,29 & 1,31 & 1,22 \\
\hline Proteína bruta & 14,74 & 14,90 & 14,50 & 3,59 & 3,85 & 3,67 & 3,57 & 3,59 \\
\hline FDNcp & 36,90 & 37,26 & 37,51 & 50,56 & 51,14 & 50,50 & 54,59 & 50,56 \\
\hline Fibra em detergente ácido & 23,39 & 24,55 & 24,12 & 32,40 & 34,30 & 33,20 & 35,10 & 32,40 \\
\hline Lignina & 5,32 & 4,55 & 4,32 & 7,23 & 5,97 & 5,54 & 5,92 & 7,23 \\
\hline Carboidratos totais & 36,49 & 33,84 & 34,45 & 91,46 & 89,04 & 89,16 & 89,18 & 91,46 \\
\hline Carboidratos não fibrosos & 78,85 & 77,38 & 77,75 & 36,30 & 31,95 & 33,02 & 29,83 & 36,30 \\
\hline Nutrientes digestíveis totais & 64,71 & 64,80 & 65,06 & 58,24 & 58,39 & 59,07 & 57,64 & 58,24 \\
\hline Digestibilidade in vitro da MS & 73,02 & 72,42 & 72,81 & 63,25 & 62,27 & 63,34 & 66,68 & 63,25 \\
\hline \multicolumn{9}{|c|}{-Composição percentual (\% da matéria seca) -- } \\
\hline Cana-de-açúcar & 61,00 & 61,00 & 62,00 & 63,00 & -- & -- & -- & -- \\
\hline Grão de milho moído & 16,45 & 16,45 & 16,02 & 15,60 & -- & -- & -- & -- \\
\hline Farelo de soja & 20,06 & 20,06 & 19,54 & 19,03 & -- & -- & -- & -- \\
\hline Núcleo mineral ${ }^{1}$ & 0,32 & 0,32 & 0,31 & 0,30 & -- & -- & -- & -- \\
\hline Calcário calcítico & 0,39 & 0,39 & 0,38 & 0,37 & -- & -- & -- & -- \\
\hline Ureia pecuária & 1,79 & 1,79 & 1,74 & 1,70 & -- & -- & -- & -- \\
\hline
\end{tabular}

$\mathrm{CN}=$ dieta com cana-de-açúcar in natura; $\mathrm{CH} 24, \mathrm{CH} 48$ e $\mathrm{CH} 72=$ dietas com cana hidrolisada armazenada por 24,48 e 72 horas, respectivamente. Cana $=$ cana in natura; $\mathrm{C} 24, \mathrm{C} 48$ e C72 = cana hidrolisada armazenada por 24,48 e 72 horas, respectivamente; FDNcp = fibra em detergente neutro corrigida pra cinzas e proteína. ${ }^{1}$ Níveis de garantia do fabricante: $\mathrm{P}=40 \mathrm{~g}, \mathrm{Ca}=146 \mathrm{~g}, \mathrm{Na}=56 \mathrm{~g}, \mathrm{~S}=40 \mathrm{~g}, \mathrm{Mg}=$ $20 \mathrm{~g}, \mathrm{Cu}=350 \mathrm{mg}, \mathrm{Zn}=1300 \mathrm{mg}, \mathrm{Mn}=900 \mathrm{mg}, \mathrm{Fe}=1050 \mathrm{mg}$, Co $=10 \mathrm{mg}, \mathrm{I}=24 \mathrm{mg}, \mathrm{Se}=10 \mathrm{mg}, \mathrm{F}$ (max.) 400mg, veículo q.s.q. 1000g.

Ciência Rural, v.43, n.6, jun, 2013. 
regulada para obtenção de partículas com tamanho de $2-3 \mathrm{~cm}$. Depois de picada, parte da cana-de-açúcar foi espalhada em camadas de $20 \mathrm{~cm}$ sobre piso de concreto em galpão coberto e adicionou-se a solução de cal com auxílio de regador. A solução foi preparada com $0,5 \mathrm{~kg}$ de cal hidratada em 2 litros de água $100 \mathrm{~kg}^{-1}$ de cana-de-açúcar. Segundo os níveis de garantia do fabricante, a cal apresenta 95,5\% de $\mathrm{Ca}(\mathrm{OH})_{2}$ e $1,5 \%$ de $\mathrm{MgO}$, o que determina que a quantidade de $\mathrm{CaO}$ total (agente hidrolizante) seja de 72,5\%. Destacase que os demais componentes, que totalizam $3 \%$ da composição da cal, não são identificados pelo fabricante. Após homogeneização da solução de cal com a cana-de-açúcar, foi realizada a concentração do material em amontoados (500kg e $80 \mathrm{~cm}$ de altura), obtendo-se a cana hidrolisada armazenada por 24,48 ou 72 horas, sendo que, na dieta com cana in natura, a forragem foi fornecida imediatamente após picagem.

As dietas foram formuladas considerando consumo de $2,4 \%$ do peso corporal para ganho de peso de $750 \mathrm{~g} \mathrm{dia}^{-1}$. A ração foi fornecida em duas refeições diárias ( $8 \mathrm{~h}$ e $14 \mathrm{~h}$ ), sendo o consumo de ração registrado diariamente e a oferta de alimentos mantida $10 \%$ acima do consumo voluntário.

A composição química das dietas foi determinada em amostras de alimentos e sobras coletadas semanalmente, pré-secas em estufa com ventilação forçada a $55^{\circ} \mathrm{C}$ por 72 horas e moídas em moinho tipo Willey, equipado com peneiras com crivos de $1 \mathrm{~mm}$ de diâmetro. Os teores de matéria seca, matéria mineral (MM), extrato etéreo (EE) e proteína bruta $(\mathrm{PB})$ foram determinados segundo AOAC (1990). O teor de fibra em detergente neutro (FDN) foi determinado segundo VAN SOEST et al.
(1991), sendo corrigida para cinzas e proteínas. Os teores de fibra em detergente ácido e lignina foram determinados segundo Van SOEST (1973). Os teores de carboidratos totais (CT) e carboidratos não fibrosos (CNF) foram determinados segundo SNIFFEN et al. (1992): $\mathrm{CT}=100-(\mathrm{PB}+\mathrm{EE}+\mathrm{MM})$ e $\mathrm{CNF}=\mathrm{CT}-\mathrm{FDN}$.

$\mathrm{O}$ teor de nutrientes digestíveis totais (NDT) foi determinado segundo WEISS (1993): NDT = (PBDcp x PB) $+($ EE $\times 2,25)+[0,98 \times(100-F D N n-P B-$ Cinzas-EE-1) $]+0,75 \times$ \{(FDNn-lignina $) \times$ [1-(lignina/ FDNn)0,667] $\}-7$, em que: PBDcp = proteína bruta digestível, determinada distintamente para forragem $\left(\mathrm{Y}=\mathrm{e}^{-0,012} \mathrm{x}\right.$ PIDA) e concentrado ( $\mathrm{Y}=1-0,004$ $\mathrm{x}$ PIDA); FDNn $=$ FDN ajustada para nitrogênio, determinada a partir da proteína em detergente neutro do resíduo do FDN $\{$ PIDN $=-8,77+(0,33 \mathrm{x}$ $\mathrm{PB})+(0,143 \times \mathrm{FDN})\}$; PIDA = proteína insolúvel em detergente ácido, determinada a partir do resíduo da FDA. A composição mineral dos volumosos e dietas (Tabela 2) foi determinada segundo metodologia descrita por SILVA \& QUEIROZ (2002).

O delineamento experimental adotado foi o inteiramente casualizado. Os dados foram submetidos à análise da variância e contrastes ortogonais, em que a soma de quadrados de tratamentos foi decomposta em três contrastes ortogonais: cana in natura $\mathrm{x}$ cana hidrolisada $\left(\begin{array}{llll}-3 & 1 & 1 & 1\end{array}\right)$ e efeito linear $\left(\begin{array}{lll}0 & -1 & 0\end{array}\right.$ 1) e quadrático $\left(\begin{array}{llll}0 & -1 & 2 & -1\end{array}\right)$ do tempo de hidrólise, considerando-se $\alpha=0,05$.

\section{RESULTADOS E DISCUSSÃO}

O consumo de matéria seca (CMS) foi superior $(\mathrm{P}<0,05)$ para as novilhas alimentadas com

Tabela 2 - Composição mineral dos volumosos e dietas.

\begin{tabular}{|c|c|c|c|c|c|c|c|c|c|}
\hline Itens & $\mathrm{Ca}^{1}$ & $\mathrm{P}^{1}$ & $\mathrm{Mg}^{1}$ & $\mathrm{~K}^{1}$ & $\mathrm{Fe}^{2}$ & $\mathrm{Mn}^{2}$ & $\mathrm{Zn}^{2}$ & $\mathrm{Cu}^{2}$ & $\mathrm{Ca}: \mathrm{P}$ \\
\hline Cana & 0,14 & 0,01 & 0,07 & 0,55 & 7,33 & 30,33 & 4,33 & 2,00 & 14,00 \\
\hline $\mathrm{C} 24$ & 0,94 & 0,03 & 0,13 & 0,68 & 303,67 & 45,67 & 11,33 & 2,33 & 31,33 \\
\hline $\mathrm{C} 48$ & 0,91 & 0,03 & 0,12 & 0,62 & 260,33 & 49,33 & 13,67 & 2,67 & 30,33 \\
\hline $\mathrm{C} 72$ & 0,95 & 0,04 & 0,13 & 0,69 & 325,33 & 49,67 & 13,33 & 2,33 & 23,75 \\
\hline $\mathrm{CN}$ & 0,54 & 0,22 & 0,14 & 0,71 & 79,90 & 39,32 & 38,57 & 10,54 & 2,46 \\
\hline $\mathrm{CH} 24$ & 1,03 & 0,23 & 0,18 & 0,71 & 260,67 & 48,67 & 42,84 & 10,74 & 4,44 \\
\hline $\mathrm{CH} 48$ & 1,00 & 0,23 & 0,17 & 0,75 & 234,86 & 50,83 & 43,43 & 10,72 & 4,45 \\
\hline $\mathrm{CH} 72$ & 1,03 & 0,23 & 0,17 & 0,79 & 276,54 & 51,06 & 42,51 & 10,32 & 4,52 \\
\hline
\end{tabular}

${ }^{1} \%$ da matéria seca; ${ }^{2} \mathrm{mg} / \mathrm{kg}$; Cana = cana in natura; $\mathrm{C} 24, \mathrm{C} 48, \mathrm{C} 72=$ cana hidrolisada armazenada por 24,48 e 72 horas, respectivamente; $\mathrm{CN}=$ dieta com cana in natura; $\mathrm{CH} 24, \mathrm{CH} 48$ e CH72 = dietas com cana hidrolisada armazenada por 24, 48 e 72 horas, respectivamente. 
dietas com cana in natura $(\mathrm{CN})$ em relação às demais, não sendo alterado pelo tempo de armazenamento da cana hidrolisada $(\mathrm{CH})$ (Tabela 3). Os resultados apresentados foram similares aos reportados por MORAES et al. (2008), que avaliando dietas com $\mathrm{CN}$ e $\mathrm{CH}$ para novilhas de 8 a 12 meses de idade, verificaram redução do CMS pela inclusão de óxido de cálcio $(\mathrm{CaO})$. Esses autores justificaram os resultados pela menor aceitabilidade da $\mathrm{CH}$, fato evidenciado neste estudo pelo comportamento ingestivo dos animais (MISSIO et al., 2012b).

A limitação do CMS pela adição de cal à cana-de-açúcar não está somente relacionada à palatabilidade do volumoso, mas também à categoria animal, visto que, para bovinos jovens, notadamente zebuínos, tem sido postulado que a aceitabilidade da CH é menor (MISSIO et al., 2012b). Ao contrário, quando a $\mathrm{CH}$ foi fornecida para animais mestiços e/ou de categorias de maior idade, como novilhas da raça Nelore, com 14-16 (MISSIO et al., 2012a) e 24 meses de idade (PINA et al., 2011), novilhas mestiças Angus-Nelore com 242kg (DOMINGUES et al., 2012), novilhas mestiças Holandês-Zebu com $200 \mathrm{~kg}$ (CARVALHO et al., 2010) e novilhos da raça Nelore confinados dos 390 aos $488,8 \mathrm{~kg}$ de peso corporal (FREITAS et al., 2011) ou vacas em lactação (ALVES et al., 2010), o CMS não foi alterado pela $\mathrm{CH}$ na dieta. Apesar de, em geral, não se verificar alteração no CMS de dietas com $\mathrm{CH}$, espera-se aumento na ingestão de alimento (FREITAS et al., 2011) como resultado do aumento da digestibilidade da fração fibrosa da forragem, como verificado por DIAS (2009).

O consumo de proteína bruta (CPB), fibra em detergente neutro (CFDN), fibra em detergente ácido(CFDA), carboidratos totais (CCT), carboidratos não fibrosos (CCNF) (kg/dia) e nutrientes digestíveis totais $(\mathrm{CNDT})$ foi superior $(\mathrm{P}<0,05)$ em dietas com $\mathrm{CN}$, em relação àquelas com $\mathrm{CH}$ (Tabela 3 ). Esses resultados discordaram do exposto na literatura (PIRES et al., 2010; MISSIO et al., 2012a), em que tem sido proposto que a ação dos agentes alcalinos sobre a fração fibrosa dos volumosos aumenta a disponibilidade de nutrientes (carboidratos solúveis e carboidratos estruturais livres da lignina), fato que geraria, em função do aumento da digestibilidade, incremento na ingestão de nutrientes.

Nas dietas com $\mathrm{CH}$, o armazenamento do volumoso não alterou $(\mathrm{P}>0,05)$ o CFDN, CFDA, CCT e CCNF (Tabela 3), reflexo do similar CMS entre as

Tabela 3 - Consumo de matéria seca e nutrientes por novilhas da raça Nelore alimentadas com cana hidrolisada armazenada por diferentes períodos.

\begin{tabular}{|c|c|c|c|c|c|c|c|c|}
\hline \multirow{2}{*}{ Consumo } & \multicolumn{4}{|c|}{ 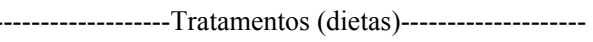 } & \multirow{2}{*}{$\mathrm{CV}(\%)$} & \multicolumn{3}{|c|}{ 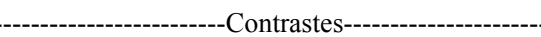 } \\
\hline & $\mathrm{CN}$ & $\mathrm{CH} 24$ & $\mathrm{CH} 48$ & $\mathrm{CH} 72$ & & $\mathrm{CI} v s \mathrm{CH}$ & Linear & Quadrático \\
\hline MS, $\mathrm{kg} \mathrm{dia}^{-1}$ & $3,77 a^{*}$ & $2,69 \mathrm{~b}$ & $2,97 b$ & $2,77 b$ & 11,15 & 0,0001 & 0,2499 & 0,0913 \\
\hline $\mathrm{PB}, \mathrm{kg} \mathrm{dia}{ }^{-1}$ & $0,60 \mathrm{a}$ & $0,42 b$ & $0,48 b$ & $0,42 b$ & 14,92 & 0,0001 & 0,7648 & 0,2089 \\
\hline FDN, $\mathrm{kg} \mathrm{dia}^{-1}$ & $1,37 \mathrm{a}$ & $0,95 \mathrm{~b}$ & $1,05 \mathrm{~b}$ & $0,98 b$ & 14,13 & 0,0002 & 0,6208 & 0,4112 \\
\hline FDA, $\mathrm{kg} \mathrm{dia}^{-1}$ & $0,77 \mathrm{a}$ & $0,50 \mathrm{~b}$ & $0,55 b$ & $0,56 \mathrm{~b}$ & 36,26 & 0,0001 & 0,4307 & 0,7997 \\
\hline $\mathrm{CT}, \mathrm{kg} \mathrm{dia}{ }^{-1}$ & $2,93 a$ & $2,04 \mathrm{~b}$ & $2,24 b$ & $2,12 b$ & 26,84 & 0,0001 & 0,5129 & 0,3860 \\
\hline $\mathrm{CNF}, \mathrm{kg} \mathrm{dia}{ }^{-1}$ & $1,44 \mathrm{a}$ & $1,09 b$ & $1,09 \mathrm{~b}$ & $1,11 \mathrm{~b}$ & 30,28 & 0,0007 & 0,9258 & 0,9166 \\
\hline NDT, $k g$ dia $^{-1}$ & $2,43 a$ & $1,62 b$ & $1,83 b$ & $1,58 b$ & 17,0 & 0,0001 & 0,6990 & 0,0673 \\
\hline MS, $\%$ PC & $2,46 b$ & $2,03 b$ & $2,14 b$ & $1,98 b$ & 11,20 & 0,0002 & 0,9975 & 0,2173 \\
\hline $\mathrm{PB}, \% \mathrm{PC}$ & $0,39 a$ & $0,32 b$ & $0,35 b$ & $0,30 \mathrm{~b}$ & 9,90 & 0,0046 & 0,8084 & 0,2128 \\
\hline FDN, \% PC & $0,89 a$ & $0,71 b$ & $0,75 b$ & $0,70 \mathrm{~b}$ & 14,10 & 0,0009 & 0,9242 & 0,3500 \\
\hline FDA, $\%$ PC & $0,50 \mathrm{a}$ & $0,38 b$ & $0,39 b$ & $0,40 \mathrm{~b}$ & 30,12 & 0,0011 & 0,6350 & 0,9858 \\
\hline $\mathrm{CT}, \% \mathrm{PC}$ & $1,89 \mathrm{a}$ & $1,54 \mathrm{~b}$ & $1,61 b$ & $1,51 \mathrm{~b}$ & 17,98 & 0,0001 & 0,9728 & 0,3356 \\
\hline $\mathrm{CNF}, \% \mathrm{PC}$ & 0,71 & 0,85 & 0,63 & 0,56 & 5,08 & 0,8319 & 0,0918 & 0,6527 \\
\hline NDT, $\%$ PC & $1,57 \mathrm{a}$ & $1,23 \mathrm{c}$ & $1,32 b$ & $1,13 \mathrm{c}$ & 9,41 & 0,0001 & 0,8799 & 0,0187 \\
\hline $\mathrm{Ca}, \mathrm{g} \mathrm{dia}^{-1}$ & $15,61 b$ & $18,03 \mathrm{a}$ & $24,13 \mathrm{a}$ & $20,80 \mathrm{a}$ & 7,43 & 0,0001 & 0,2695 & 0,0911 \\
\hline $\mathrm{P}, \mathrm{g} \mathrm{dia}^{-1}$ & $6,31 \mathrm{a}$ & $4,71 \mathrm{~b}$ & $5,64 b$ & $5,21 \mathrm{~b}$ & 11,61 & 0,0001 & 0,1929 & 0,2302 \\
\hline $\mathrm{Ca} / \mathrm{P}$ & $2,47 b$ & $3,85 \mathrm{a}$ & $4,27 \mathrm{a}$ & $3,98 \mathrm{a}$ & 7,34 & 0,0001 & 0,0918 & 0,3103 \\
\hline
\end{tabular}

*Médias seguidas de letras minúsculas distintas na linha diferem $(\mathrm{P}<0,05)$ pela análise de contrastes ortogonais (Cana in natura versus cana hidrolisada, efeito linear e quadrático do tempo de hidrólise); $\mathrm{CN}$ : dieta com cana in natura; $\mathrm{CH} 24, \mathrm{CH} 48$ e $\mathrm{CH} 72=$ dietas com cana hidrolisada armazenada por 24, 48 e 72 horas, respectivamente; MS = matéria seca; $\mathrm{PB}=$ proteína bruta; FDN = fibra em detergente neutro; $\mathrm{FDA}=$ fibra em detergente ácido; $\mathrm{CT}=$ carboidratos totais; $\mathrm{CNF}=$ carboidratos não fibrosos; $\mathrm{NDT}=$ nutrientes digestíveis totais; $\mathrm{Ca} / \mathrm{P}=$ relação cálcio/fósforo da dieta consumida; $\mathrm{PC}=$ peso corporal.

Ciência Rural, v.43, n.6, jun, 2013. 
dietas com $\mathrm{CH}$. Esses resultados demonstraram que o período de armazenamento avaliado não alterou o valor nutritivo da forragem a ponto de alterar o consumo das frações alimentares mencionadas. MOTA et al. (2010) verificaram que o tratamento da cana-de-açúcar com $0,5 \%$ de $\mathrm{CaO}$ ou hidróxido de cálcio $\left(\mathrm{Ca}(\mathrm{OH})_{2}\right)$ não alterou o valor nutritivo da forragem, permitindo sua utilização após 60 horas de armazenamento. DOMINGUES et al. (2012) verificaram que o armazenamento da cana-de-açúcar tratada com $\mathrm{CaO}(0,5$ e $1 \%$ na matéria natural) até 72 horas não alterou o consumo de nutrientes, com exceção do CFDN, que diminuiu com o aumento do tempo de armazenamento da forragem.

$\mathrm{O}$ tempo de armazenamento da $\mathrm{CH}$ determinou variação quadrática $(\mathrm{P}<0,05)$ no CNDT (\% do peso corporal), sendo esse maior em dietas com $\mathrm{CH}$ armazenada por 48 horas (Tabela 3), todavia, esses resultados não foram suficientes para compensar a redução no CMS em relação à dieta com $\mathrm{CN}$ e alterar o desempenho animal. O aumento do CNDT ocorrido pelo fornecimento de dietas com $\mathrm{CH}$ armazenada por 48 horas, em relação às com 24 horas, foi associado à melhora da digestibilidade da forragem. Já a redução do CNDT nas dietas com $\mathrm{CH}$ armazenada por 72 horas foi resultado da redução do valor energético do volumoso (Tabela 1). Vale ressaltar que a diminuição do teor energético da $\mathrm{CH}$ durante o armazenamento está relacionado com a degradação de açúcares solúveis por leveduras e fungos, apesar das cales serem efetivas na melhora da estabilidade aeróbica da $\mathrm{CH}$, em relação à $\mathrm{CN}$ (DOMINGUES et al., 2011).

O consumo de cálcio, bem como a relação cálcio/fósforo ingerida, foi superior $(\mathrm{P}<0,05)$ nas dietas com $\mathrm{CH}$ em relação às dietas com $\mathrm{CN}$ (Tabela 3 ). Esses resultados foram condizentes com os resultados obtidos por MOTA et al. (2010) e PINA et al. (2011), os quais verificaram aumento do teor de cálcio da canade-açúcar pela adição de $\mathrm{CaO}$ e $\mathrm{Ca}(\mathrm{OH})_{2}$, tal como nesta pesquisa (Tabela 2). Ressalta-se que a elevação na ingestão de cálcio, bem como da relação cálcio/ fósforo, manteve-se dentro de limites adequados para bovinos, melhorando o suprimento de cálcio frente às exigências nutricionais (NRC, 1996). Nota-se ainda, que a adição de $\mathrm{Ca}(\mathrm{OH})_{2}$, além de determinar variações na quantidade de cálcio da forragem tratada em relação à in natura, determinou variações na concentração dos demais minerais da forragem (Tabela 2), indicando a presença de outros minerais na cal além do Ca. Vale lembrar que o processamento de rochas calcárias para a produção de compostos mais reativos, tal como as cales microprocessadas, traz como benefício a obtenção de produtos livres de elementos tóxicos ou com concentração desses elementos muito abaixo da concentração tóxica para ruminantes, tal como verificado por DOMINGUES (2009).

$\mathrm{O}$ consumo de fósforo foi maior $(\mathrm{P}<0,05)$ nas dietas com $\mathrm{CN}$ em relação àquelas com $\mathrm{CH}$ (Tabela 3), reflexo do maior CMS. Por outro lado, o consumo de fósforo, bem como o de cálcio e a relação $\mathrm{Ca} / \mathrm{P}$ ingerida não foram alterados $(\mathrm{P}>0,05)$ pelo tempo de armazenamento da $\mathrm{CH}$, já que o $\mathrm{CMS}$ e o teor desses minerais na forragem (Tabela 2) não foram alterados pelo armazenamento da $\mathrm{CH}$. Esses resultados estão de acordo com os obtidos por MOTA et al. (2010), os quais verificaram que o tempo de armazenamento da $\mathrm{CH}$ com $\mathrm{CaO}$ ou $\mathrm{Ca}(\mathrm{OH})_{2}$ por até 60 horas não alterou a concentração de cálcio e fósforo na forragem.

Em função da superioridade no CMS, as novilhas alimentadas com $\mathrm{CN}$ apresentaram maior $(\mathrm{P}<0,05)$ ganho de peso médio diário, bem como maior peso corporal e escore corporal ao final do experimento que as novilhas alimentadas com $\mathrm{CH}$ (Tabela 4). Esses resultados foram similares aos verificados por MORAES et al. (2008) e PINA et al. (2011), em que o menor desempenho dos animais alimentados com $\mathrm{CH}$ foi associado ao menor CMS. Por outro lado, quando o CMS não foi limitado pela adição de cal à cana-de-açúcar, o desempenho animal não foi prejudicado pela utilização da $\mathrm{CH}$ na dieta (CARVALHO et al., 2010; FREITAS et al., 2011; DOMINGUES et al., 2012), evidenciando que a possibilidade de sucesso com a utilização de $\mathrm{CH}$ na dieta de bovinos é mais provável quando seu fornecimento não estiver associado a categorias em que o CMS é limitado pela palatabilidade da forragem.

$\mathrm{O}$ armazenamento da $\mathrm{CH}$ entre 24 e 72 horas não alterou $(\mathrm{P}>0,05)$ o ganho de médio diário, $\mathrm{o}$ peso corporal final e a condição corporal final (Tabela 4), resultados similares aos verificados por PINA et al. (2011) e DOMINGUES et al. (2012). Segundo PINA et al. (2011), a possibilidade de estocagem da cana-de-açúcar por um período de 72 horas seria uma das vantagens do processo de hidrólise, em virtude das melhorarias sobre a logística das propriedades e redução dos custos associados com o corte, transporte e trituração do material.

A conversão alimentar e a eficiência energética não foram alterados $(\mathrm{P}>0,05)$ pelo tratamento da cana-de-açúcar com $\mathrm{Ca}(\mathrm{OH})_{2}$, bem como pelo tempo de armazenamento da $\mathrm{CH}$ (Tabela 4), concordando com os resultados obtidos 
Tabela 4 - Peso e condição corporal, desempenho e eficiência alimentar de novilhas da raça Nelore alimentadas com cana hidrolisada armazenada por diferentes períodos.

\begin{tabular}{|c|c|c|c|c|c|c|c|c|}
\hline \multirow{3}{*}{ Variáveis } & & & ds) & & \multirow{3}{*}{ CV $(\%)$} & \multirow{2}{*}{\multicolumn{3}{|c|}{--Contrastes------ }} \\
\hline & & & & & & & & \\
\hline & $\mathrm{CN}$ & $\mathrm{CH} 24$ & $\mathrm{CH} 48$ & $\mathrm{CH} 72$ & & $\mathrm{CI} v s \mathrm{CH}$ & Linear & Quadrático \\
\hline PI, kg & 121,6 & 118,0 & 117,2 & 121,8 & 7,80 & -- & -- & -- \\
\hline ECI, pontos & 1,87 & 1,83 & 1,77 & 1,72 & 7,90 & -- & -- & -- \\
\hline $\mathrm{PF}, \mathrm{kg}$ & $187,9 \mathrm{a}^{*}$ & $157,5 \mathrm{~b}$ & $163,4 b$ & $164,6 \mathrm{~b}$ & 11,09 & 0,0013 & 0,2760 & 0,4749 \\
\hline GMD, kg & $0,79 a$ & $0,47 \mathrm{~b}$ & $0,55 \mathrm{~b}$ & $0,51 b$ & 22,24 & 0,0024 & 0,1388 & 0,0871 \\
\hline $\begin{array}{l}\text { ECF, } \\
\text { pontos }\end{array}$ & $3,46 a$ & $2,85 \mathrm{~b}$ & $3,25 b$ & $3,15 b$ & 5,70 & 0,0062 & 0,1003 & 0,9538 \\
\hline $\mathrm{CA}, \mathrm{kg} \mathrm{kg}^{-1}$ & 4,77 & 5,72 & 5,40 & 5,43 & 18,56 & 0,2925 & 0,9638 & 0,3411 \\
\hline $\begin{array}{l}\mathrm{EE}, \quad \text { Mcal } \\
\mathrm{kg}^{-2}\end{array}$ & 13,56 & 15,20 & 14,67 & 13,66 & 12,09 & 0,2506 & 0,7134 & 0,2713 \\
\hline
\end{tabular}

*Médias seguidas de letras minúsculas distintas na linha diferem $(\mathrm{P}<0,05)$ pela análise de contrastes ortogonais (Cana in natura versus cana hidrolisada, efeito linear e quadrático do tempo de armazenamento da cana hidrolisada); $\mathrm{CN}=$ dieta com cana in natura; $\mathrm{CH} 24$, $\mathrm{CH} 48$ e $\mathrm{CH} 72$ = dietas com cana hidrolisada armazenada por 24, 48 e 72 horas, respectivamente; PI = peso corporal inicial; PF = peso corporal final; $\mathrm{GMD}=$ ganho de peso médio diário; $\mathrm{ECI}=$ escore corporal inicial; ECF = escore corporal final; $\mathrm{CA}=$ conversão alimentar $(\mathrm{kg}$ de matéria seca $\mathrm{kg}^{-1}$ de ganho de peso corporal); $\mathrm{EE}=$ eficiência energética (Mcal kg-1 de ganho de peso corporal); $1 \mathrm{~kg}$ de NDT = 4,4Mcal (NRC, 1996).

por DOMINGUES et al. (2012). Esses resultados evidenciam que as alterações na composição química da forragem (Tabela 1) pela adição do $\mathrm{Ca}(\mathrm{OH})_{2}$, e pelo armazenamento da forragem não foram suficientes para aumentar a eficiência de utilização de dietas com cana hidrolisada por bovinos jovens.

\section{CONCLUSÃO}

Dietas com elevada proporção de canade-açúcar hidrolisada não são recomendadas para alimentação de novilhas Nelore, em virtude da adição de $0,5 \%$ de hidróxido de cálcio, na matéria natural, limitar a ingestão de alimento e reduzir o ganho de peso.

Apesar do consumo de alimento e o ganho de peso não serem alterados entre dietas que apresentem a cana-de-açúcar tratada com hidróxido de cálcio em diferentes tempos de armazenamento, a hidrólise com cal hidratada não deve ser recomendada como método de conservação de forragem quando o alimento for destinado para categorias em que a palatabilidade do volumoso limita a ingestão.

\section{REFERÊNCIAS}

ALVES, A.C.N. et al. Desempenho produtivo de vacas mestiças alimentadas com cana-de-açúcar hidrolisada e in natura. Nucleus Animalium, v.2, n.2, p.99-106, 2010. Disponível em: <http:// www.nucleus.feituverava.com.br/index.php/animalium/article/ view/497>. Acesso em: 18 jul. 2012. doi: 10.3738/1982.2278-497.
ASSOCIATION OF OFFICIAL ANALYTICAL CHEMISTS (AOAC). Official methods of analysis. 15.ed. Washington, D.C., 1990. 1141p.

CARVALHO, G.G.P. et al. Consumo e digestibilidade aparente em novilhas alimentadas com dietas contendo cana-de-açúcar tratada com óxido de cálcio. Revista Brasileira de Zootecnia, v.39, n.12, p.2703-2713, 2010. Disponível em: < http://www.scielo.br/pdf/rbz/ v39n12/a22v39n12.pdf $>$. Acesso em: 18 jul. 2012. doi: 10.1590/ S1516-35982010001200022.

DIAS, A.M. Hidróxido de cálcio como aditivo para cana-deaçúcar in natura para alimentação de bovinos. 2009. 106f. Tese (Doutorado em Zootecnia) - Universidade Estadual de Maringá, Maringá, PR.

DOMINGUES, F.N. Cana-de-açúcar hidrolisada com doses crescentes de cal virgem e tempos de exposição ao ar para a alimentação de bovinos. 2009. 93f. Tese (Doutorado em Zootecnia) - Faculdade de Ciências Agrárias e Veterinárias, Jaboticabal, SP.

DOMINGUES, F.N. et al. Estabilidade aeróbia, pH e dinâmica de desenvolvimento de microrganismos da cana-de-açúcar in natura hidrolisada com cal virgem. Revista Brasileira de Zootecnia, v.40, n.4, p.715-719, 2011. Disponível em: <http://www.scielo. br/pdf/rbz/v40n4/03.pdf $>$. Acesso em: 18 jul. 2012. doi: 10.1590/ S1516-35982011000400003.

DOMINGUES, F.N. et al. Desempenho de novilhas de corte alimentadas com cana hidrolisada. Ciência Animal Brasileira, v.13, n.1, p.8-14, 2012. Disponível em: <http://www.revistas.ufg. br/index.php/vet/article/view/8396/10548>. Acesso em: 18 jul. 2012. doi: 10.5216/cab.v13i1.8396.

FREITAS, A.W.P. et al. Desempenho de novilhos recebendo dietas à base de cana-de-açúcar in natura ou hidrolisada. Revista Brasileira de Zootecnia, v.40, n.11, p.2532-2537, 2011. Disponível em: <http://www.scielo.br/scielo.php?pid=S1516-

Ciência Rural, v.43, n.6, jun, 2013. 
35982011001100035\&script $=$ sci_arttext $>$. Acesso em: 18 jul. 2012. doi: 10.5216/cab.v13i1.8396.

MAGALHÃES, A.L.R. et al. Cana-de-açúcar em substituição à silagem de milho em dietas para vacas em lactação: desempenho e viabilidade econômica. Revista Brasileira de Zootecnia, v.33, n.5, p.1292-1302, 2004.

MISSIO, R.L. et al. Digestion of feed fractions and intake of heifers fed hydrolyzed sugarcane stored for different periods. Revista Brasileira de Zootecnia, v.41, n.7, p.1737-1746, 2012a Disponível em: <http://www.revista.sbz.org.br/artigo/index. php?artigo $=66745>$. Acesso em: 26 jul. 2012a. doi: 10.1590/ S1516-35982012000700025.

MISSIO, R.L. et al. Characteristics of forage and feeding behavior of Nellore heifers fed with hydrolyzed sugarcane. Revista Brasileira de Zootecnia, v.41, n.9, p.2092-2100, 2012b. Disponível em: $<$ http://www.revista.sbz.org.br/artigo/index. php? artigo $=66800>$. Acesso em: 28 set. 2012 b. doi: $10.1590 /$ S1516-35982012000900018.

MORAES, K.A.K. et al. Cana-de-açúcar tratada com óxido de cálcio fornecida com diferentes níveis de concentrado para novilhas de corte em confinamento. Revista Brasileira de Zootecnia, v.37, n.7, p.1293-1300, 2008. Disponível em: $<$ http://www.scielo.br/scielo.php?script=sci_arttext\&pid $=$ S1516-35982008000700022 $>$. Acesso em: 18 jul. 2012. doi: 10.1590/S1516-35982008000700022.

MOTA, D.A. et al. Hidrólise da cana-de-açúcar com cal virgem ou cal hidratada. Revista Brasileira de Zootecnia, v.39, n.6, p.1186-1190, 2010. Disponível em: <http://www.scielo.br/scielo. php?pid $=$ S 1516-35982010000600004\&script $=$ sci_arttext $>$. Acesso em: 18 jul. 2012. doi: 10.1590/S1516-35982010000600004.

NATIONAL RESEARCH COUNCIL (NRC). Nutrients requirements of beef cattle. 7.ed. Washington, D.C., 1996. 242 p.
PANCOTI, C.G. et al. Valor nutritivo da cana-de-açúcar adicionada com óxido de cálcio para novilhas Holandês x Zebu. Arquivo Brasileiro de Medicina Veterinária e Zootecnia, v.63, n.4, p.905-913, 2011. Disponível em: <http://www.scielo. br/scielo.php?pid=S0102-09352011000400016\&script $=$ sci arttext>. Acesso em: 27 nov. 2012. doi: 10.1590/S010209352011000400016 .

PINA, D.S. et al. Efeitos da inclusão e dos tempos de exposição da cana-de-açúcar ao óxido de cálcio sobre os parâmetros digestivos e o desempenho de novilhas nelores. Revista Brasileira de Zootecnia, v.40, n.3, p.648-656, 2011. Disponível em: <http:// www.scielo.br/pdf/rbz/v39n7/a26v39n7.pdf>. Acesso em: 18 jul. 2012. doi: 10.1590/S1516-35982011000300025.

PIRES, A.J.V. et al. Chemical treatment of roughage. Revista Brasileira de Zootecnia, v.39, supl esp, p.192-203, 2010. Disponível em: <http://www.scielo.br/pdf/rbz/v39sspe/22. pdf $>$. Acesso em: 18 jul. 2012. doi: 10.1590/S151635982010001300022

SILVA, D.J.; QUEIROZ, C.A. Análise de alimentos (Métodos químicos e biológicos). 2.ed. Viçosa: UFV, 2002. 165p.

SNIFFEN, C.J. et al. A new carbohydrate and protein system for evaluating cattle diets. II. Carbohydrate and protein availability. Journal of Animal Science, v.70, n.12, p.3562$3577,1992$.

VAN SOEST, P.J. Collaborative study of acid detergent fiber and lignin. Journal of the Association of Official Analytical Chemists, v.56, p.81-784, 1973.

VAN SOEST, P.J. et al. Methods for dietary fiber, neutral detergent fiber, and nonstarch polysaccharides in relation to animal nutrition. Journal of Dairy Science, v.74, p.3583-3597, 1991.

WEISS, W.P. Method estimates available energy value for ruminants. Feedstuffs, v.9, p.13-14, 1993. 